Article

\title{
An Ab Initio Study of Vacancies in Disordered Magnetic Systems: A Case Study of Fe-Rich Fe-Al Phases
}

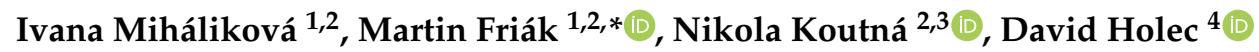 \\ and Mojmír Šob $5,1,6$ (D) \\ 1 Institute of Physics of Materials, Czech Academy of Sciences, Žižkova 22, CZ-616 62 Brno, \\ Czech Republic; mihalikova@ipm.cz (I.M.); mojmir@ipm.cz (M.Š.) \\ 2 Department of Condensed Matter Physics, Faculty of Science, Masaryk University, Kotlářská 2, \\ CZ-611 37 Brno, Czech Republic; nikola.koutna@tuwien.ac.at \\ 3 Institute of Materials Science and Technology, TU Wien, Getreidemarkt 9, A-1060 Vienna, Austria \\ 4 Department of Materials Science, Montanuniversität Leoben, Franz-Josef-Strasse 18, A-8700 Leoben, Austria; \\ david.holec@unileoben.ac.at \\ 5 Department of Chemistry, Faculty of Science, Masaryk University, Kotlářská 2, CZ-611 37 Brno, Czech Republic \\ 6 Central European Institute of Technology, CEITEC MU, Masaryk University, Kamenice 5, CZ-625 00 Brno, \\ Czech Republic \\ * Correspondence: friak@ipm.cz
}

Received: 30 March 2019; Accepted: 28 April 2019; Published: 2 May 2019

\begin{abstract}
We have performed quantum-mechanical calculations to examine the impact of disorder on thermodynamic, structural and electronic (magnetic) properties of $\mathrm{Fe}-\mathrm{Al}$ systems with vacancies. A series of supercells was used and their properties were computed employing density-functional theory (DFT) as implemented in the VASP package. Our case study is primarily aimed at a disordered solid solution $\mathrm{Fe}_{81.25} \mathrm{Al}_{18.75}$ but we have compared our results also with those obtained for the ordered $\mathrm{Fe}_{3} \mathrm{Al}$ intermetallic compound for which experimental data exist in literature. Both phases are found in Fe-Al-based superalloys. The Fe-18.75at.\%Al solid solution was simulated using special quasirandom structures (SQS) in three different disordered states with a different distribution of $\mathrm{Al}$ atoms. In particular, we have considered a general disordered case (an A2-like variant), the case without the first nearest neighbor Al-Al pairs (a B2-like distribution of atoms) and also the case without both the first and second nearest neighbor $\mathrm{Al}$-Al pairs (the $\mathrm{D0}_{3}$-like variant, in fact, an Fe-rich $\mathrm{Fe}_{3} \mathrm{Al}$ phase). The vacancy formation energies as well as the volumes of (fully relaxed) supercells with vacancies showed a large scatter for the disordered systems. The vacancy formation energies decrease with increasing concentration of $\mathrm{Al}$ atoms in the first coordination shell around the vacancy (an anti-correlation) for all disordered cases studied. The computed volumes of vacancies were found significantly lower (by 25-60\%) when compared with the equilibrium volume of the missing atoms in their elemental states. Lastly, we have analyzed interactions between the vacancies and the Fe atoms and evaluated vacancy-induced changes in local magnetic moments of Fe atoms.
\end{abstract}

Keywords: $\mathrm{Fe}_{3} \mathrm{Al}$; $\mathrm{Fe}-\mathrm{Al}$; vacancies; magnetism; ab initio; disorder; superalloys

\section{Introduction}

Vacancies are among the most frequently occurring defects in solids. Their concentration and importance grow with increasing temperature, in particular when approaching the melting point. Their higher concentrations can be, nevertheless, found also in samples at low temperatures after quenching higher-temperature states containing higher numbers of vacancies and taking advantage of sluggish kinetics at lower temperatures. 
The complexity of vacancy-containing systems increases with increasing number of sublattices (where each of them represents atomic sites with a specific local crystallographic environment), the number of chemical species present in studied materials and, last but not least, other degrees of freedom involved (such as different magnetic states which we consider below). The topic of our current research is the impact of disorder on vacancy-related characteristics in magnetic systems. As far as experimental studies are concerned, positron annihilation is one of methods which is sensitive to vacancies, see, e.g., Refs [1-9] but the obtained information is often averaged rather than specific to one type of vacancies. In contrast to that, quantum-mechanical calculations can provide atomic-scale site-specific information about each particular type of vacancies including those in magnetic systems, see, e.g., Refs. [1-7,10-21].

In our study we focus on magnetic disordered Fe-rich Fe-Al phases. Our choice is motivated by the fact that these materials can have the concentration of quenched-in vacancies as high as a few percent [22-24]. Iron-aluminides are interesting for their possible high-temperature applications due to their oxidation resistance [25], stability in molten salts [26], relatively low density, electrical resistivity and low cost of raw materials [27-29]. Their wider use is partly hampered by their environmental embrittlement [30-33] but there is recently a renewed interest in these materials [25,34-43], including also Fe-Al-based nanocomposites [44-57]. A subset of these nanocomposites is constituted by so-called superalloys consisting of an ordered $\mathrm{Fe}_{3} \mathrm{Al}$ intermetallic compound with the $\mathrm{D}_{3}$ structure (see Figure 1) and a disordered solid solution of about 18.75 at.\% $\mathrm{Al}$ in the Fe matrix, see, e.g., Refs. [46,48,58,59]; we study both below.
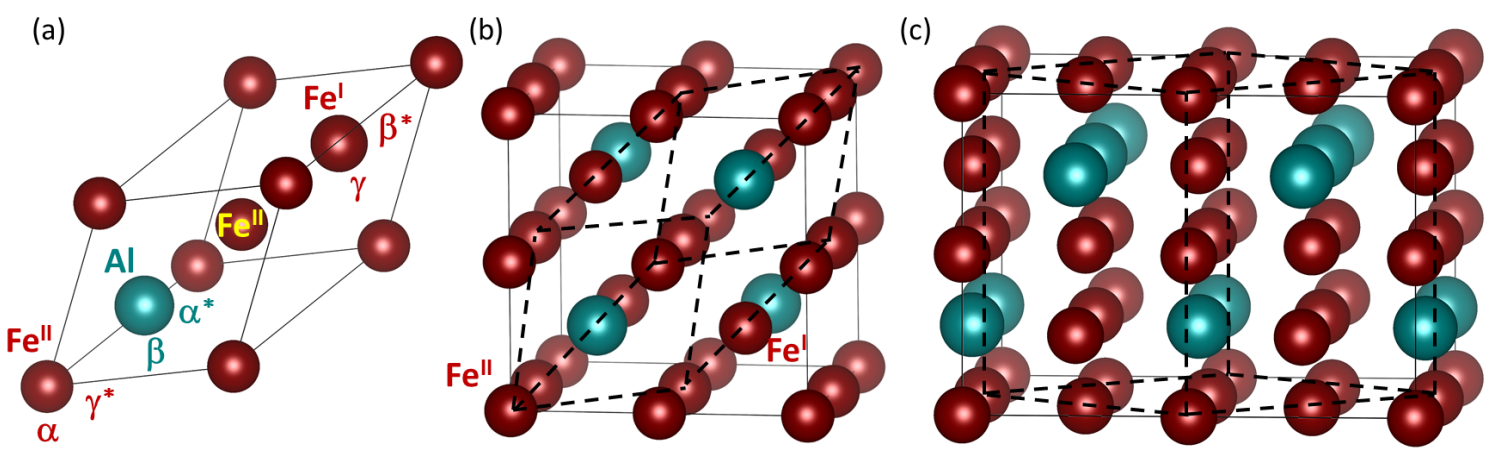

Figure 1. Visualizations of (a) a 4-atom primitive cell of $\mathrm{Fe}_{3} \mathrm{Al}$, (b) a cubic-shape 16-atom elementary supercell of $\mathrm{Fe}_{3} \mathrm{Al}$ with dashed lines showing schematically crystallographic relation between the 4-atom and 16-atom cells (a face-centered-cubic-like arrangement of 4-atomic primitive cell), and (c), a 32-atom $\sqrt{2} \times \sqrt{2} \times 1$ (times 16 atoms) supercell of $\mathrm{Fe}_{3} \mathrm{Al}$ with dashed lines indicating crystallographic relation between the 16-atom and 32-atom cells. Different sublattices are often denoted by either Greek letters or Arabic or Roman numbers as upper indexes. Regarding the Greek-letter nomenclature, the Fe sublattices are marked as $\alpha$ (Fe sites with $8 \mathrm{Fe}$ atoms in the 1st coordination shell) and $\gamma$ (Fe sites with $4 \mathrm{Fe}$ and $4 \mathrm{Al}$ atoms in the 1st nearest neighbour shell) and the $\mathrm{Al}$ sublattice is denoted by $\beta$-see, for instance Refs. [5,6,60]. As far as the upper Roman number indexes are concerned, see, e.g., Ref. [61], they reflect the fact that the $\mathrm{Fe}^{\mathrm{II}}$ sites are twice as abundant as the $\mathrm{Fe}^{\mathrm{I}}$ sites. Regarding the upper Arabic number indexes $\left(\mathrm{Fe}^{1}\right.$ and $\mathrm{Fe}^{2}$ ), they have the identical meaning reflecting different abundances (see, e.g., Ref. [62]). An alternative use of Greek letters can be found in Ref. [63] where the Al sublattice is denoted $\alpha$ (we show it as $\alpha^{*}$ in part (a) in order not to confuse with the other nomenclature), the $\mathrm{Fe}^{\mathrm{I}}$ sites is denoted by $\beta$ (it is visualized as $\beta^{*}$ in part (a)) and the Fe $\mathrm{e}^{\mathrm{II}}$ sublattice is denoted $\gamma\left(\right.$ shown as $\gamma^{*}$ ).

\section{Methods}

Our ab initio calculations were performed within the framework of density functional theory $[64,65]$ with the help of the Vienna Ab initio Simulation Package (VASP) [66-68]. The exchange and correlation energy was treated in the generalized gradient approximation (GGA) as parametrized 
by Perdew and Wang (PW91) [69] using projector augmented wave (PAW) pseudopotentials [70] and the Vosko-Wilk-Nusair correction [71]. We have employed a carefully chosen parametrization (Perdew-Wang, PW91) of the generalized gradient approximation (GGA) and a computational set-up which ensures that the experimental $\mathrm{DO}_{3}$ ground-state structure of $\mathrm{Fe}_{3} \mathrm{Al}$ is reproduced. Based on convergence tests, we used a plane-wave energy cut-off of $350 \mathrm{eV}$ and a $6 \times 6 \times 10$ Monkhorst-Pack [72] k-point mesh in the case of 32-atom $\sqrt{2} \times \sqrt{2} \times 1$ (times 16 atoms) supercells for calculations of properties of individual phases (see Figure 1c and Figure 2a-d). Our calculations discussed below simulate the vacancy concentration of $3.125 \%$ and periodic boundary conditions apply. Regarding $\mathrm{Fe}_{3} \mathrm{Al}$ intermetallic compound, two crystallographically different atomic sites for $\mathrm{Fe}$ atoms exist: $\mathrm{Fe}^{\mathrm{I}}$ atoms ( $\gamma$ sublattice) and $\mathrm{Fe}^{\mathrm{II}}$ atoms ( $\alpha$ sublattice), see Figure $1 \mathrm{a}$. The $\mathrm{Fe}^{\mathrm{II}}$ atoms are surrounded by $4 \mathrm{Fe}^{\mathrm{I}}$ atoms and $4 \mathrm{Al}$ atoms ( $\beta$ sublattice) and each of these two 4-atom neighbor groups form a tetrahedron with atoms being mutually all the 3rd nearest neighbors. The ordered intermetallic compound $\mathrm{Fe}_{3} \mathrm{Al}$ is also visualized using a 32-atom supercell (Figure 1c) with the composition $\mathrm{Fe}_{24} \mathrm{Al}_{8}$. A crystallographic relation of this 32-atom representation of $\mathrm{Fe}_{3} \mathrm{Al}$ and its cubic-shape 16-atom cell is schematically shown in Figure $1 \mathrm{c}$ by the dashed lines. The 32-atom supercell of $\mathrm{Fe}_{3} \mathrm{Al}$ is then visualized also in Figure 2a with the individual atoms numbered.

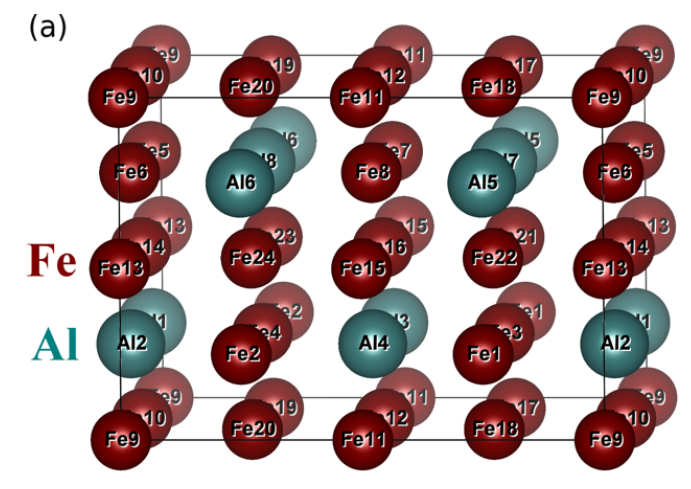

(b)
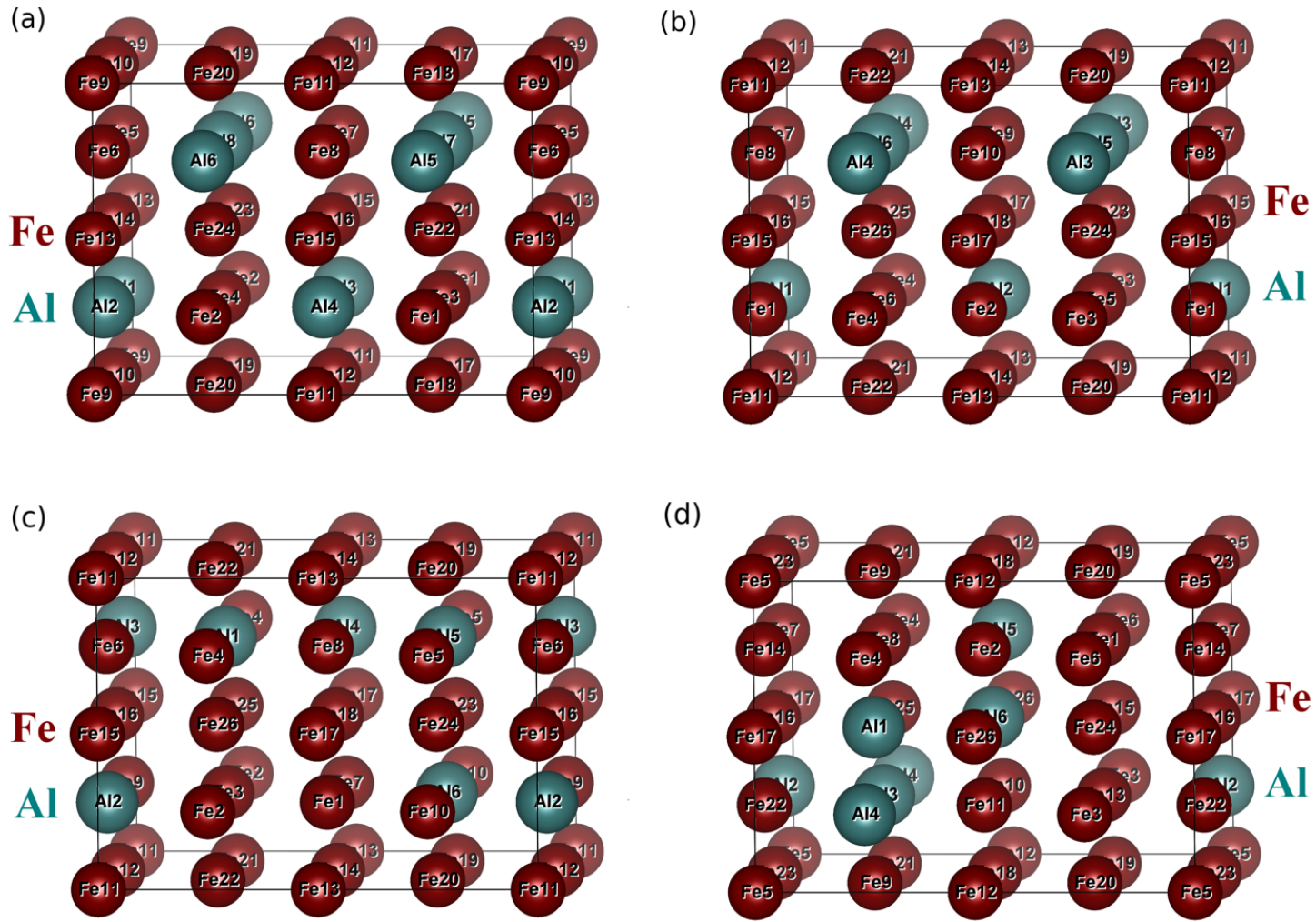

(d)

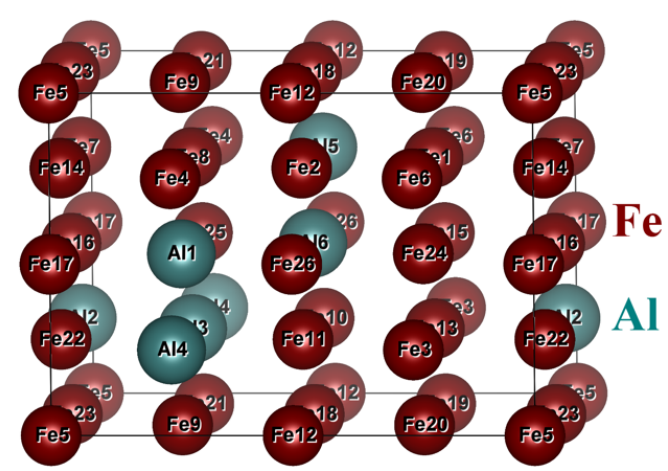

Figure 2. Schematic visualization of 32-atom $\sqrt{2} \times \sqrt{2} \times 1$ (times 16 atoms) supercells used in our ab initio calculations: (a) model of ordered $\mathrm{Fe}_{3} \mathrm{Al}$ compound with the supercell stoichiometry $\mathrm{Fe}_{24} \mathrm{Al}_{8}$, (b) SQS without the 1st and 2nd nearest neighbour $\mathrm{Al}$-Al pairs (in fact Fe-rich $\mathrm{Fe}_{3} \mathrm{Al}, \mathrm{DO}_{3}$-like structure) with the supercell stoichiometry $\mathrm{Fe}_{26} \mathrm{Al}_{6}$, (c) SQS without the 1st nearest neighbour Al-Al pairs (B2-like structure) with the supercell stoichiometry $\mathrm{Fe}_{26} \mathrm{Al}_{6},(\mathbf{d})$ model of the general disordered phase representing SQS (A2-like structure) with the supercell stoichiometry $\mathrm{Fe}_{26} \mathrm{Al}_{6}$. The numbering of individual atoms will be essential for discussion of our computed results below.

The numbering allows to put three supercells representing three disordered $\mathrm{Fe}-18.75$ at.\% $\mathrm{Al}$ states into a crystallographic context of $\mathrm{Fe}_{3} \mathrm{Al}$ compound, see Figure $2 \mathrm{~b}-\mathrm{d}$. When designing the models of the disordered $\mathrm{Fe}_{81.25} \mathrm{Al}_{18.75}$ phase we used a concept of special quasi-random structure (SQS) [73] 
generated by USPEX code [74-76]. The used 32-atom supercells (Figure 2b-d) offer a wide range of distributions of aluminium atoms in the disordered Fe-Al phase and also a higher number of non-equivalent atomic positions. These three models for the disordered $\mathrm{Fe}-18.75$ at.\% $\mathrm{Al}$ states contain the $\mathrm{Fe}$ and $\mathrm{Al}$ atoms according to the formula $\mathrm{Fe}_{26} \mathrm{Al}_{6}$.

In order to examine the energy cost of a vacancy introduction in a material (the vacancy formation energy, $E_{\mathrm{f}}$ ) we employ the formula

$$
E_{\mathrm{f}}=E_{\mathrm{def}}-E_{\mathrm{perf}}+\sum_{x} n_{x}^{\mathrm{vac}} E_{x}
$$

where $E_{\text {def }}$ is total energy of the defected system, $E_{\text {perf }}$ is total energy of the vacancy-free system, $n_{x}^{\mathrm{vac}}$ represents the number of missing atoms in the supercells and $E_{x}$ is their chemical potential (bcc ferromagnetic Fe and fcc non-magnetic $\mathrm{Al}$ ).

\section{Results}

Before we proceed with calculations of vacancies in disordered $\mathrm{Fe}-\mathrm{Al}$ states, which are the main topic of our study, we first test our methodology in the case of the $\mathrm{Fe}_{3} \mathrm{Al}$ intermetallic compound, which has been intensively studied in the past both theoretically and experimentally. Our computed vacancy formation energies for all three possible types of vacancies are summarized in Table 1 together with other computational as well as experimental data.

Table 1. Vacancy formation energies of $\mathrm{Fe}_{3} \mathrm{Al}$ compound (with 3.125 at.\% vacancies). Theoretical values were reported in the following studies: Kuriplach [6], Deniszczyk et al. [7], Fähnle et al. [60], Muratov et al. [63], Mayer et al. [5]. Experimental values of vacancy formation energies were obtained by Doppler broadening (DB) and positron lifetime measurements (LT) as reported by Wolff et al. [77].

\begin{tabular}{l|cccccccc}
\hline Reference & This Work & {$[6]$} & {$[7]$} & {$[60]$} & {$[63]$} & {$[5]$} & {$[77]$} & {$[77]$} \\
\hline Method & GGA PW91 & GGA PW91 & GGA PBE96 & LDA & LDA & LDA & DB & LT \\
\hline $\mathrm{E}_{f}(\mathrm{Fe} \alpha)[\mathrm{eV}]$ & 1.04 & 0.88 & 1.19 & 1.18 & 1.26 & 1.25 & 1.08 & 0.92 \\
$\mathrm{E}_{f}(\mathrm{Fe} \gamma)[\mathrm{eV}]$ & 1.90 & 1.70 & 1.90 & 2.45 & 2.36 & 2.27 & & \\
$\mathrm{E}_{f}(\mathrm{Al} \beta)[\mathrm{eV}]$ & 2.52 & 1.85 & 2.50 & 1.53 & 3.23 & 1.38 & & \\
\hline
\end{tabular}

Our theoretically obtained vacancy formation energies $E_{\mathrm{f}}$ in the case of the $\mathrm{Fe}_{3} \mathrm{Al}$ compound are in a very good agreement with the previous theoretical values reported by Kuriplach [6] and Deniszczyk et al. [7] employing generalized gradient approximation (GGA). On the other hand, the vacancy formation energies calculated by other groups using local density approximation (LDA) are not only quantitatively but also qualitatively different. In particular, according to Fähnle et al. [60] and Mayer et al. [5] the Al vacancy formation energies are lower than those of the Fe vacancies on the $\gamma$ sublattice, while we and the other GGA calculations [6,7] predict the opposite relation. Unfortunately, experimental data of Fe vacancy formation energies by Wolff et al. acquired by Doppler broadening (DB) and positron lifetime measurements (LT) are not compared with values for the Al sublattice in these two studies. Moreover, in the study by Wolff et al. [77] it was not specified from which sublattice the missing Fe atoms are. According to our calculated values of vacancy formation energies, it may be deduced that vacancies studied in those papers are formed on the $\alpha$ sublattice as these are the easiest defects to be created.

After successfully testing our methodology, as a next step, we considered vacancies in the disordered Fe-Al systems. Here the vacancy formation energies are found sensitive to the chemical composition and distribution of atoms around the vacancy. Consequently, ranges of vacancy formation energies are obtained instead of a single value for each sublattice as it was the case in the $\mathrm{Fe}_{3} \mathrm{Al}$. Considering the most disordered $\mathrm{Fe}_{81.25} \mathrm{Al}_{18.75}$ phase modeled by a fully disordered SQS structure (the A2-like variant shown in Figure 2d), the formation energies of Fe vacancies span from 1.601 to $2.232 \mathrm{eV}$ and those of $\mathrm{Al}$ vacancies are predicted to be from 2.118 to $2.751 \mathrm{eV}$. As we are not aware of any 
experimental vacancy formation energies for the simulated composition $\left(\mathrm{Fe}_{81.25} \mathrm{Al}_{18.75}\right)$, a comparison with experimental data can be only indirect. Focusing on the energies of Fe vacancies, Schaefer et al. [61] investigated the formation of $\mathrm{Fe}$ vacancies in $\mathrm{Fe}_{76.3} \mathrm{Al}_{23.7}$ using the positron lifetime measurements and their detected value, $1.18 \mathrm{eV}$, is not very far from the lower bound of our theoretical values, i.e., $1.601 \mathrm{eV}$. Under other conditions, Wolff et al. examined $\mathrm{Fe}_{93} \mathrm{Al}_{7}$ (i.e., a lower $\mathrm{Al}$ concentration) by Doppler broadening measurement and reported the value of $1.37 \mathrm{eV}$. Therefore, both the experiments and our calculations show a qualitatively similar trend: the vacancy formation energies grow when lowering the concentration of Al.

The above identified tendency is further examined by analyzing the calculated formation energies $E_{\mathrm{f}}$ of $\mathrm{Fe}$ and $\mathrm{Al}$ vacancies as functions of concentrations of $\mathrm{Al}$ atoms found in the first and second coordination sphere around the vacancy. The results are shown in Figure 3 and reveal interesting trends: the vacancy formation energy decreases with increasing concentration of $\mathrm{Al}$ atoms in the 1st coordination shell for both Fe and $\mathrm{Al}$ vacancies, see Figure 3a,c. Regarding the concentration of $\mathrm{Al}$ atoms in the 2nd coordination shells (see Figure $3 b, d$ ), the trends are much less pronounced and much more difficult to be identified. The Fe vacancy formation energies seem to sharply increase for the $\mathrm{Al}$ concentration between 0 at.\% and 16.67 at.\% (1 out of 6 ) and then stay rather constant with a weak wavy pattern (see Figure $3 b$ ). The tendencies in the data points related to the $\mathrm{Al}$ vacancy formation energies as a function of the Al concentration in 2nd coordination shell around vacancies (see Figure 3d) are even less pronounced. All these results nevertheless illustrate a remarkable sensitivity of vacancy formation energies to the distribution and chemical composition of atoms in their neighboring sites.

(a)

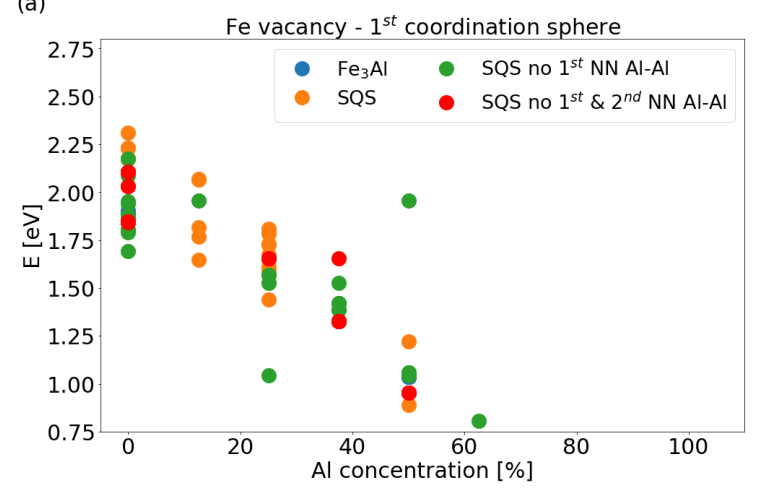

(c)

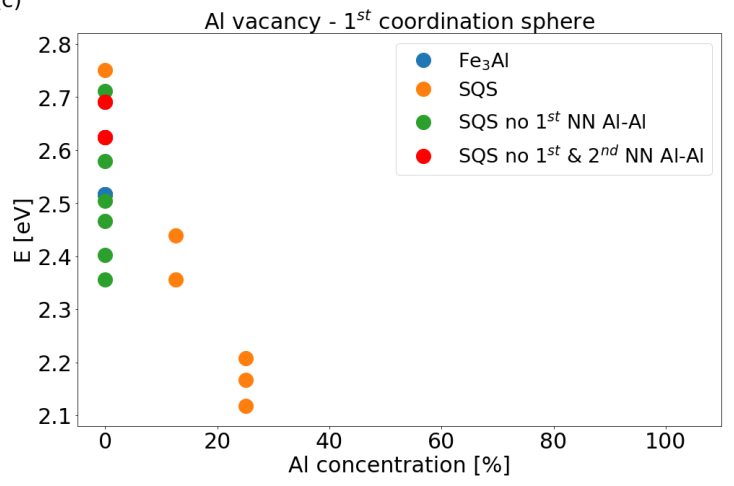

(b)

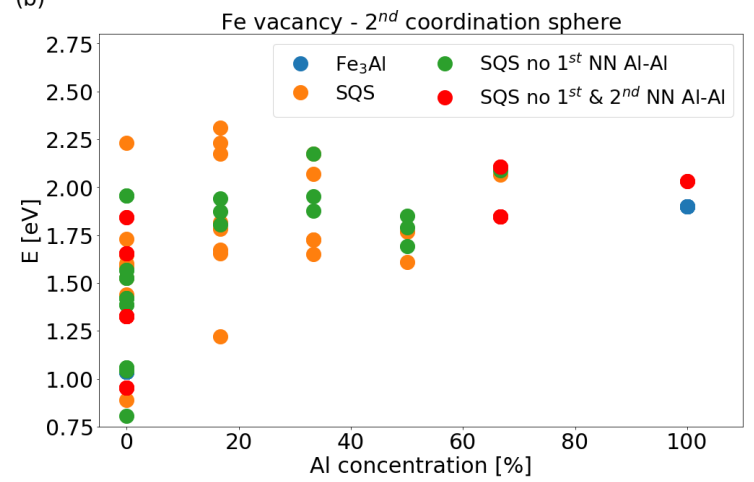

(d)

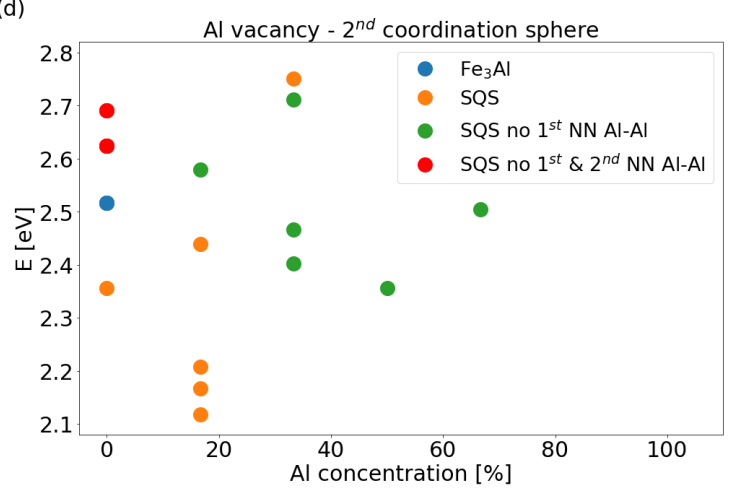

Figure 3. Vacancy formation energies in the studied phases as functions of concentration of $\mathrm{Al}$ atoms in the coordination shells around the removed atom: for the Fe vacancy (a) in the 1st (b) and the 2nd coordination shell, and for Al vacancy (c) in the 1st (d) and the 2nd shell.

The results in Figure 3 were obtained when fully adapting the volume and supercell shape to the presence of a vacancy by minimizing the energy. This approach corresponds to the situation when the 
matrix surrounding the vacancies is soft enough to adapt in this way and as a model it corresponds to the rather high simulated vacancy concentration. As another extreme we can imagine a scenario when the concentration of vacancies is very low and a large defect-free matrix further apart from a vacancy would be hard enough to keep the interatomic distances and volume as in the defect-free state. For comparison, we have calculated the vacancy formation energies of Fe atoms also for the latter scenario and our results are shown in Appendix A. Importantly, the above discussed trends are the same.

Next to the energies, our calculations also allow for determining the changes of the overall volume and the total magnetic moment of the studied systems, i.e., the supercells used in our calculations. Our results related to the overall volume and the magnetic moment of the supercells are summarized in Figure 4a,b, respectively. The results obtained for the three simulated disordered states are compared with those for the ordered $\mathrm{Fe}_{3} \mathrm{Al}$ intermetallic compound. The values of the total magnetic moments and the volume for each simulated system without vacancies are taken as references. The results shown in Figure 4 are then evaluated so that these references are subtracted from the values obtained for vacancy-containing supercells. Focusing first on the vacancy-induced changes in the total magnetic moments in Figure 4a, it is possible to see a trend when a removal of $\mathrm{Al}$ atoms in any of the four studied systems (full blue circles in Figure 4a) leads to an increase of the total magnetic moment. This impact is most visible in the case of the ordered $\mathrm{Fe}_{3} \mathrm{Al}$ intermetallic compound (the left-most column of data points in Figure 4a). This finding is in agreement with the lowering of magnetic moment of the Fe atoms with increasing number of $\mathrm{Al}$ atoms in the first coordination shell which was theoretically identified earlier in Ref. [78] or in our recent publications [79,80]. In an opposite manner, a removal of Fe atoms typically leads to a lowering of the total magnetic moment (full red-brown circles in Figure 4a). Here the lowering is smaller in the case of $\mathrm{Fe}_{3} \mathrm{Al}$ and more significant for the computed disordered systems. The maximum reduction of the total magnetic moments (the most negative values in Figure 4a) are those computed for vacancies in the disordered systems.

(a)

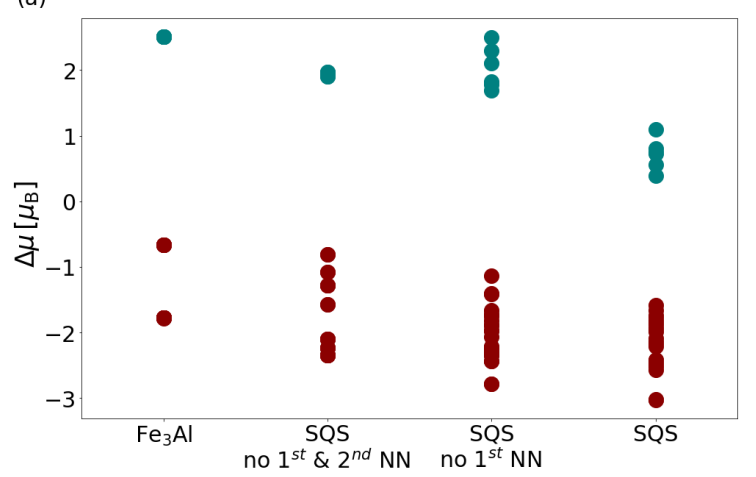

(b)

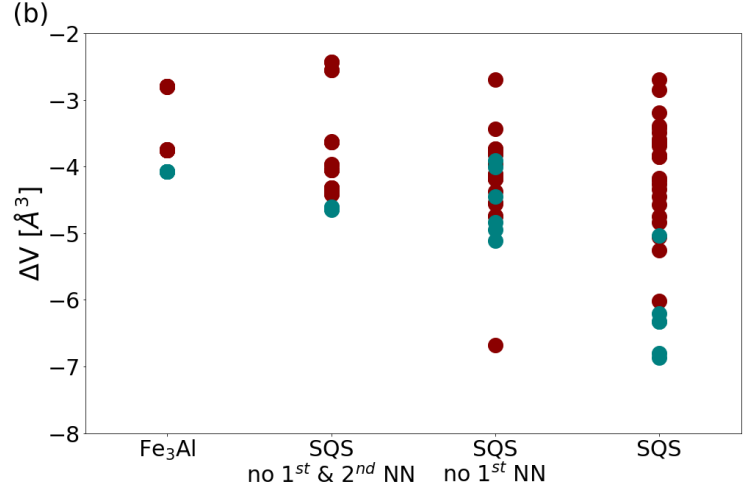

Figure 4. Computed changes of the overall magnetic moment (a) and volume (b) of supercells shown in Figure $3 \mathrm{a}-\mathrm{d}$. The data points are organized in vertical columns for each calculated supercell.

As far as the volumetric changes are concerned, see Figure $4 b$, the minimum volume reduction is predicted for $\mathrm{Fe}^{\mathrm{I}}$-like atoms in the disordered supercell without any first and second nearest neighbor $\mathrm{Al}-\mathrm{Al}$ pairs, the $\mathrm{D0}_{3}$-like case, i.e., the $\mathrm{Fe}$-rich $\mathrm{Fe}_{3} \mathrm{Al}$ and in the case of $\mathrm{Fe}^{\mathrm{I}}$ atoms ( $\gamma$ sublattice) in the $\mathrm{Fe}_{3} \mathrm{Al}$. The other extreme, the maximum volumetric reduction is predicted for $\mathrm{Al}$ vacancies in a general SQS with a disorder in all sublattices, the A2-like state (full blue circles in the right-most column of data points in Figure 4b). Next, we will compare the volumetric changes induced by the missing atoms with the equilibrium volume of these absent atoms in their elemental phases.

Figure 5 summarizes our results with the calculated volumes of the $\mathrm{Al}$ and $\mathrm{Fe}$ vacancies visualized relatively to the equilibrium volume of the non-magnetic face-centered-cubic (fcc) $\mathrm{Al}$ and ferromagnetic 
body-centered-cubic (bcc) Fe, respectively. The volumes of $\mathrm{Al}$ vacancies are between $25 \%$ and $42 \%$ of the equilibrium volume of non-magnetic fcc Al. The volumes of Fe vacancies span over a yet broader range with the lower bound very similar as in the $\mathrm{Al}$ case but the upper one is close to $60 \%$ of the equilibrium volume of FM bcc Fe. Next we will analyze the sensitivity of local atomic moments to the chemical composition of the neighborhoodand distribution of atoms. In order to examine the changes induced by the presence of vacancies, we first show the local magnetic moments of atoms in vacancy-free supercells - their values are displayed in Figure 6.

(a)

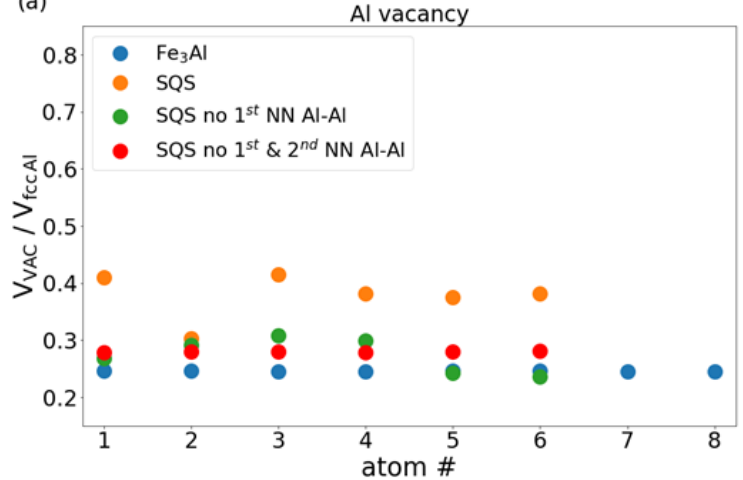

(b)

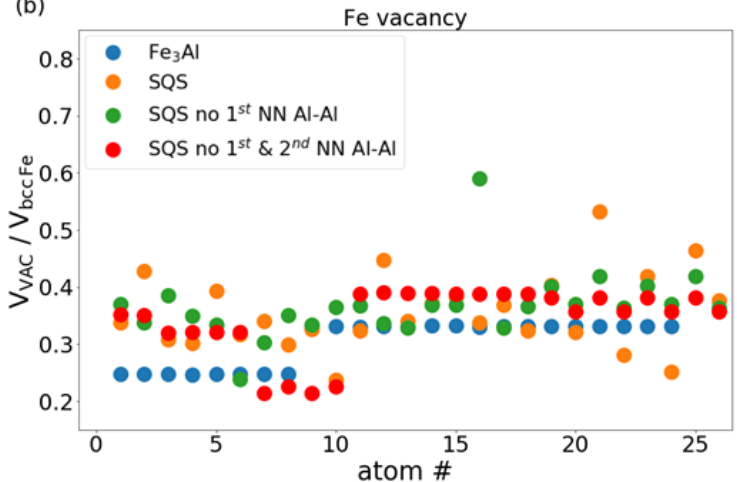

Figure 5. Computed volumes of $\mathrm{Al}(\mathbf{a})$ and $\mathrm{Fe}(\mathbf{b})$ vacancies expressed relatively with respect to the equilibrium volume of $\mathrm{Al}$ atom in the non-magnetic face-centered-cubic (fcc) $\mathrm{Al}$ and ferromagnetic body-centered-cubic (bcc) Fe, respectively.

(a)

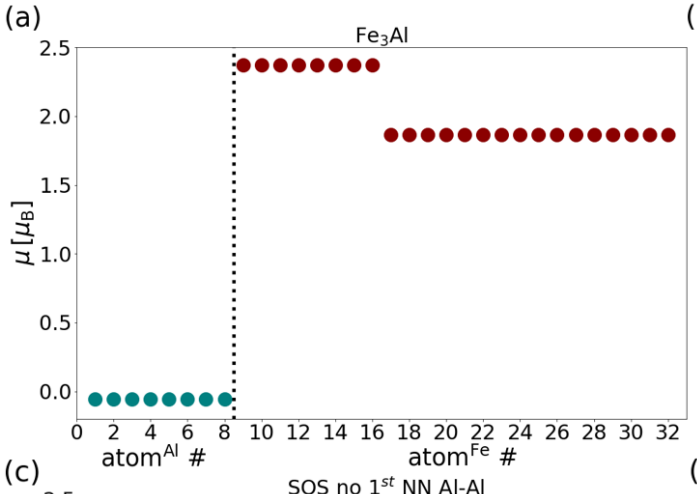

(b)

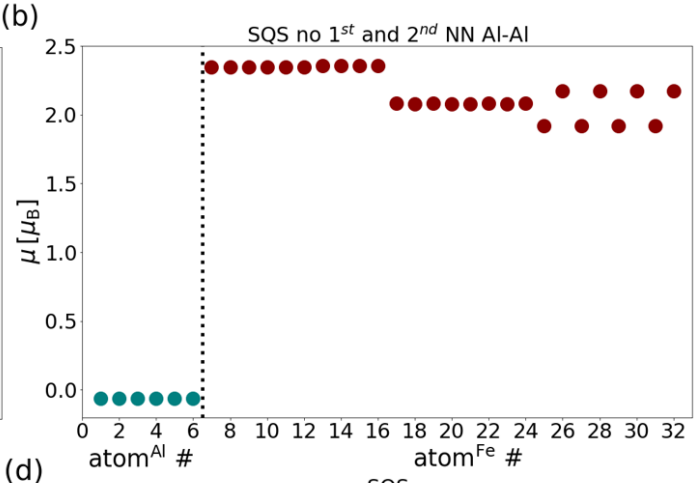

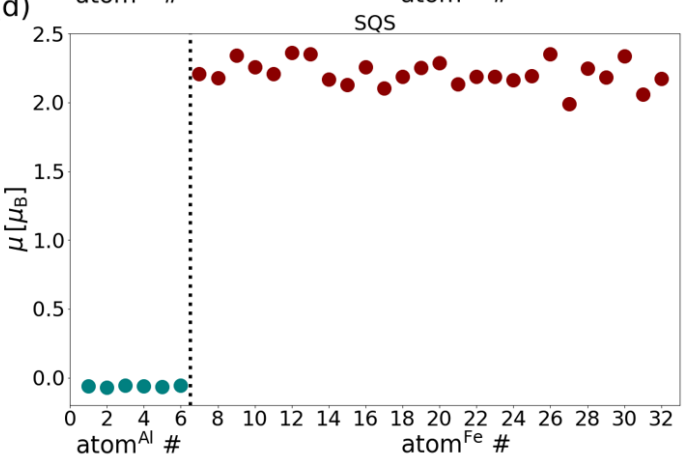

Figure 6. Dependencies of local magnetic moments on numbers of individual atoms in all studied phases: (a) stoichiometry $\mathrm{Fe}_{24} \mathrm{Al}_{8}-8 \mathrm{Al}$ atoms with numbers from 1 to $8,8 \mathrm{Fe}^{\mathrm{I}}$ atoms (sublattice $\gamma$ ) with numbers from 9 to 16 and $16 \mathrm{Fe}^{\mathrm{II}}$ atoms (sublattice $\alpha$ ) with numbers from 16 to 32 , (b-d) stoichiometry $\mathrm{Fe}_{26} \mathrm{Al}_{6}-6 \mathrm{Al}$ atoms with numbers from 1 to 6 and $26 \mathrm{Fe}$ atoms with numbers from 7 to 32 (data points for $\mathrm{Al}$ and $\mathrm{Fe}$ atoms are separated by vertical dotted lines). 
In the case of the ordered $\mathrm{Fe}_{3} \mathrm{Al}$ intermetallic compound (Figure 6a), the local magnetic moments of $\mathrm{Al}$ atoms are almost zero $\left(-0.057 \mu_{\mathrm{B}}\right)$ and the $\mathrm{Fe}^{\mathrm{I}}$ atoms on the sublattice $\gamma$ have a higher magnitude of the local magnetic moment $\left(2.374 \mu_{\mathrm{B}}\right)$ than $\mathrm{Fe}^{\mathrm{II}}$ atoms on the sublattice $\alpha\left(1.866 \mu_{\mathrm{B}}\right)$. This is in agreement with results of previous theoretical studies, see e.g., Ref. [78], which showed that the magnitude of the local magnetic moment of Fe atoms decreases with increasing concentration of $\mathrm{Al}$ atoms in the first coordination sphere. Here the $\mathrm{Fe}^{\mathrm{I}}$ atoms with a higher magnetic moment have 8 $\mathrm{Fe}$ atoms in their first coordination sphere while the $\mathrm{Fe}^{\mathrm{II}}$ atoms with a lower magnetic moment have only $4 \mathrm{Fe}$ atoms and $4 \mathrm{Al}$ atoms in the first coordination shell. In cases of disordered Fe-Al models (Figure $6 \mathrm{~b}-\mathrm{d}$ ), it is difficult to determine a clear pattern. While $\mathrm{Al}$ atoms exhibit almost zero values of magnetic moments (from -0.072 to $-0.056 \mu_{\mathrm{B}}$ ), Fe atoms possess local magnetic moments from a wide range of values (from $1.696 \mu_{\mathrm{B}}$ to $2.437 \mu_{\mathrm{B}}$ ). The disorder, which involves different local atomic environments of many atoms, lifts the degeneracy. Therefore, the local magnetic moments cover a range of values rather than a single value. Interestingly, the scatter of these values of local magnetic moments are not simply correlated with the level of simulated disorder. In particular, the maximum scatter of values is visible in Figure $6 \mathrm{c}$ which corresponds to the situation when there are no first-nearest neighbor Al-Al pairs (B2-like distribution of atoms) and the A2-like disordered case (Figure 6d) is characterized by a narrower range of values. A possible explanation can be that all Fe atoms obtain rather similar disordered environment, which does differ for each atom but there are no longer any sublattices which offer specific surroundings (and thus values of local magnetic moments which are clearly different from more disordered sites).

Having discussed the local magnetic moments of atoms in vacancy-free cases, we proceed to vacancy-containing states and vacancy-induced changes of local magnetic moments at atoms around simulated vacancies. In particular, we evaluate dependencies of changes in local magnetic moments $\left(\Delta \mu^{\mathrm{Fe}}=\mu_{\mathrm{vac}}^{\mathrm{Fe}}-\mu_{\text {perf }}^{\mathrm{Fe}}\right)$ on individual atoms in all studied phases. As we systematically take away one Fe atom at a time, one Fe atom after another, we obtain for each Fe atom up to 25 different values of its local magnetic moment corresponding to the case when one of the other 25 atoms (often in a different distance and in a different crystallographic direction) is removed. Figure 7 summarizes our results, i.e., the vacancy-induced changes of the local magnetic moments as a function of the local magnetic moment of the monitored Fe atom in the vacancy-free state (see the values in Figure 6).

Discussing the ordered $\mathrm{Fe}_{3} \mathrm{Al}$ case first, there are two different values of local magnetic moments of Fe atoms on different sublattices shown (see Figure 6a) and, therefore, there are two vertical columns of data points showing changes of the local magnetic moment of these two different types of Fe atoms when different other atoms are removed. Figure 7 a shows that the vacancy-induced changes are both negative and positive and within the range from -0.2 to $0.3 \mu_{\mathrm{B}}$.

When focusing on the Fe-18.75 at.\%Al disordered system, Figure 7 neatly shows how the increasing level of disorder leads to a higher number of different local magnetic moments in the vacancy-free case (corresponding to a higher number of vertical columns of data points representing the changes in the local magnetic moment) and how differently these crystallographically non-equivalent Fe atoms respond to the presence of Fe vacancies in different distances and different crystallographic directions. Here we limit ourselves to Fe vacancies only as they have lower formation energies and are more probable to occur. The visualization in Figure 7 shows that the vacancy-induced changes in local magnetic moments of Fe atoms are within a fairly wide range from -0.4 to $0.3 \mu_{\mathrm{B}}$.

While Figure 7 shows the magnitude of vacancy-induced changes of the local magnetic moment of atoms which remain in the material (vertical axis) as a function of the local magnetic moment which the removed atom has in a vacancy-free material (horizontal axis), it does not provide information about how these changes depend on the distance of the Fe atoms from the vacancy. Motivated by the dependencies published in the case of interstitial atoms (see, e.g., Ref. [81]), we visualize these trends in Figure 8. Besides the magnitude of changes of the local magnetic moments (vertical scatter of data points) the Figure 8 neatly illustrates also the variations of inter-atomic distances in the vacancy-free states due to the disordered distribution of atoms (horizontal scatter of data points). 
(a)

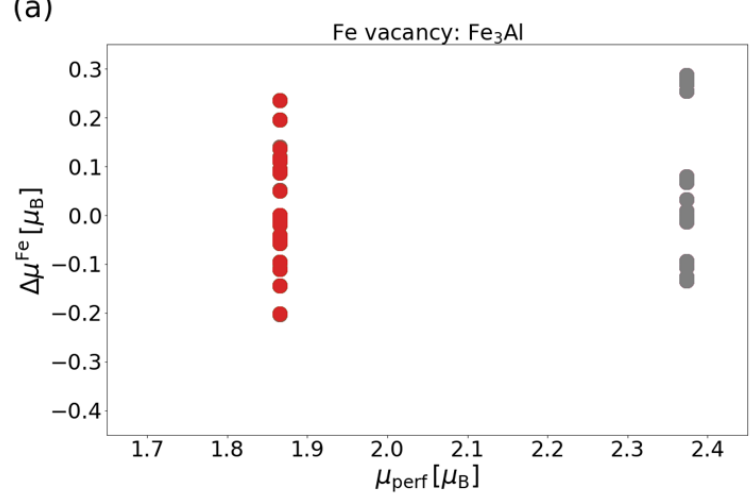

(c)

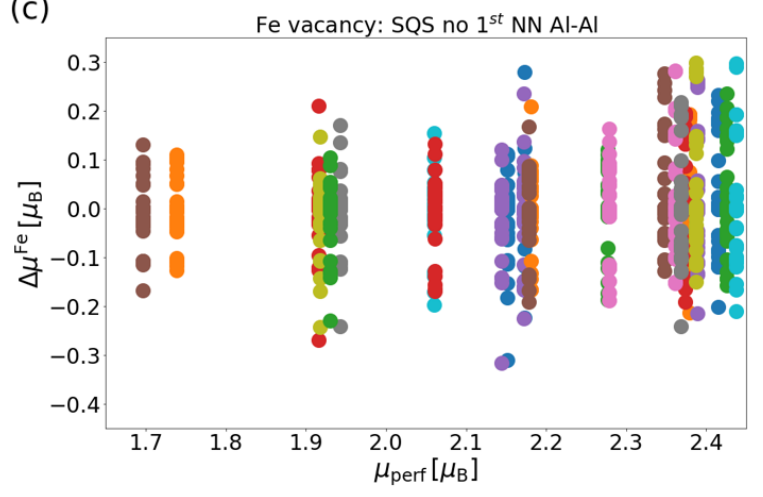

(b)

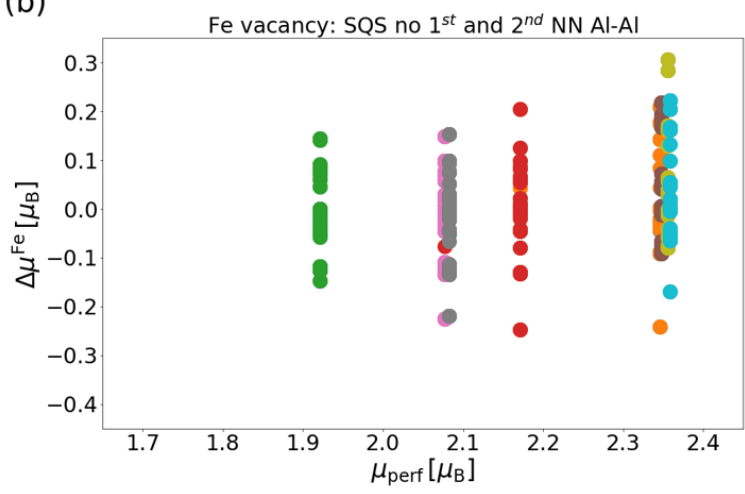

(d)

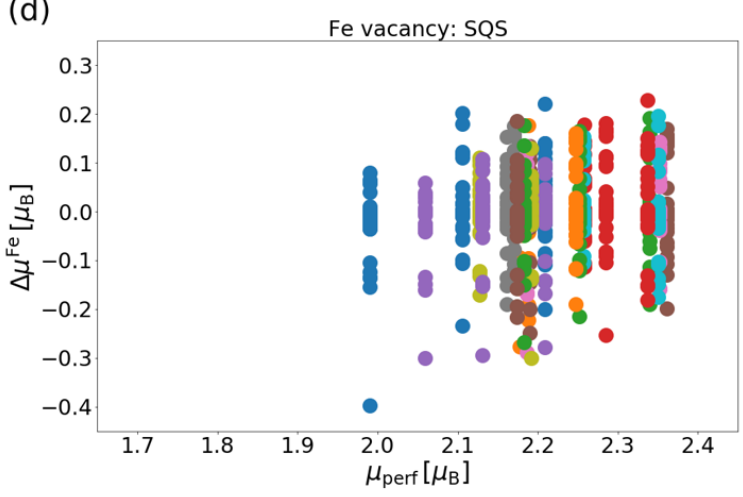

Figure 7. Change in local magnetic moments $\Delta \mu^{\mathrm{Fe}}$ as a function of local magnetic moments of atoms in vacancy-free supercells: (a) ordered $\mathrm{Fe}_{3} \mathrm{Al}$ intermetallic compound, (b) SQS without the 1st and 2nd nearest neighbour $\mathrm{Al}-\mathrm{Al}$ pairs (in fact $\mathrm{Fe}-\mathrm{rich} \mathrm{Fe}_{3} \mathrm{Al}$ ), (c) SQS without the 1st nearest neighbour $\mathrm{Al}-\mathrm{Al}$ pairs (B2-like structure), (d) a fully disordered phase SQS (A2-like structure).

As seen in Figure 8, the changes of the local magnetic moments clearly decrease with the increasing distance from the vacancy only in the case of the general SQS, see Figure $8 \mathrm{~d}$. As far as the other states are concerned, see Figure $8 \mathrm{a}-\mathrm{c}$, the connection between the vacancy-induced changes and the distance from it are much less pronounced. This finding can indicate a complex interplay of changes of the local magnetic moments via rather long-distance interactions and coupling of different (structural, compositional, electronic, magnetic and vibrational) degrees of freedom.

Lastly, when considering methodological aspects, it should be stated that our use of special quasi-random structures when modeling vacancies is only one of a few alternatives. The other options include the application of Monte Carlo simulations, see, e.g., Refs. [82,83] or the use of cluster expansion technique, see, for example, Refs. [84,85]. As another limitation of our approach it is worth mentioning that the vacancies change the pair-distribution functions originally evaluated when generating the vacancy-free supercells (see them in Figure 2). Consequently, there are subtle and complex consequences as far as thermodynamic and statistical aspects of the studied systems are concerned. For a proper approach to these aspects see, for example, a recent publication [86]. These will be the topic of future studies. 
(a)
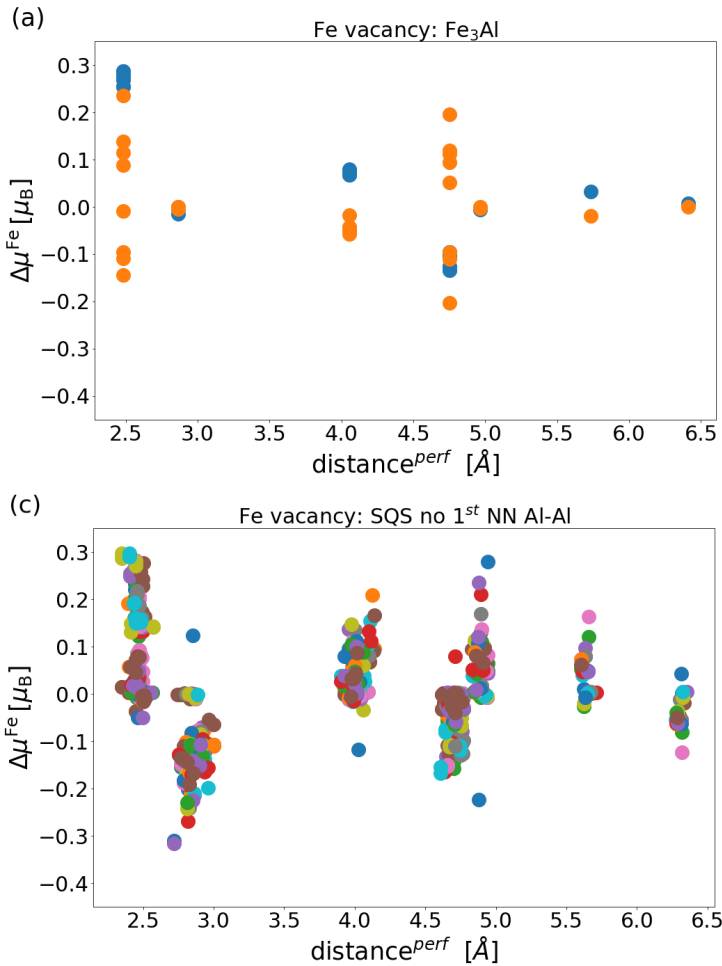

(b)

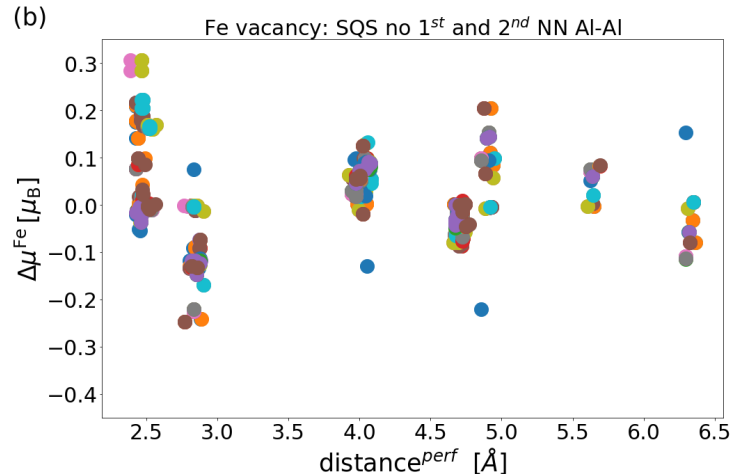

(d)

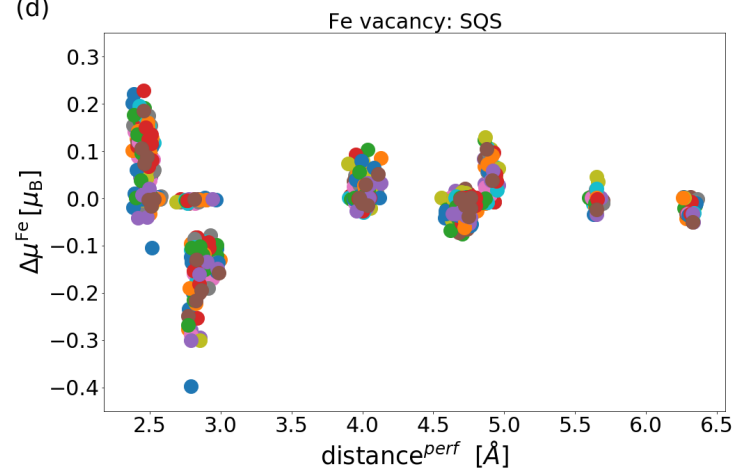

Figure 8. Change in local magnetic moments of the Fe atoms $\Delta \mu^{\mathrm{Fe}}$ as a function of the distance of studied atoms from the vacancy (measured in the vacancy-free states): (a) ordered $\mathrm{Fe}_{3} \mathrm{Al}$ intermetallic compound, (b) SQS without the 1st and 2nd nearest neighbour Al-Al pairs, (c) SQS without the 1st nearest neighbour Al-Al pairs (B2-like structure), (d) a general disordered phase SQS (A2-like structure).

\section{Conclusions}

We have performed a series of quantum-mechanical calculations to analyze thermodynamic, structural and magnetic properties of two $\mathrm{Fe}-\mathrm{Al}$ phases with vacancies. Our computational set-up and, in particular, the parametrization (Perdew-Wang, PW91) of the generalized gradient approximation (GGA), were carefully chosen so as to ensure that the experimental $\mathrm{D0}_{3}$ ground-state structure of $\mathrm{Fe}_{3} \mathrm{Al}$ is reproduced. Our calculated vacancy formation energies in the case of ordered $\mathrm{Fe}_{3} \mathrm{Al}$ intermetallic compound (1.04 eV, $1.90 \mathrm{eV}$ and $2.52 \mathrm{eV}$ for the $\alpha$-sublattice $\mathrm{Fe}, \gamma$-sublattice $\mathrm{Fe}$ and $\mathrm{Al}$ vacancies, respectively), are in agreement with both previous theoretical GGA values and published experimental data $(0.92-1.08 \mathrm{eV})$ for $\mathrm{Fe}$ vacancies at the $\alpha$-sublattice. The $\mathrm{Fe}_{3} \mathrm{Al}$ case was studied as a test of our methodology but we were primarily interested in a disordered solid solution $\mathrm{Fe}_{81.25} \mathrm{Al}_{18.75}$. To simulate it we used special quasirandom structures (SQS) to model three different disordered states with different distribution of $\mathrm{Al}$ atoms in this material. In particular, we have considered a general disordered case without any sublattices (an A2-like variant), the distribution of atoms without the first nearest neighbor Al-Al pairs (a B2-like case) and also the case when both the first and second nearest neighbor $\mathrm{Al}$-Al pairs are eliminated (the $\mathrm{D0}_{3}$-like variant of an $\mathrm{Fe}$-rich $\mathrm{Fe}_{3} \mathrm{Al}$ ).

As a main conclusion of our study, a remarkable sensitivity of vacancy formation energies, their volumes and changes of local magnetic moments of neighboring Fe atoms on the chemical composition around the vacancy was found. The vacancy formation energies as well as the volumes of (fully relaxed) supercells with vacancies showed a large scatter for the disordered systems. They mostly decrease with increasing concentration of $\mathrm{Al}$ atoms in the first coordination shell around the vacancy for all calculated disordered cases. Dependencies on the chemical and structural distribution of atoms in the second shell are less clear but nearly opposite trends (increasing and nearly constants formation 
energies as a function of the concentration of $\mathrm{Al}$ atoms) neatly illustrate the complexity of vacancies in disordered systems.

The volumes of vacancies were found significantly lower (by as much as $75 \%$ ) when compared with the volumes of the missing atoms in their elemental forms. Finally, we have analyzed interactions between the vacancies and the Fe atoms and evaluated vacancy-induced changes in local magnetic moments of $\mathrm{Fe}$ atoms. These changes of the local atomic moments were found within a range from -0.4 to $0.3 \mu_{\mathrm{B}}$.

Considering how rich and complex are the phenomena related to the vacancies in disordered magnetic systems, we hope that our work will motivate future studies in this area (see, for example, recent works in Refs. [20,21]). Not only experimental but also theoretical studies would be highly desirable as quantum-mechanical calculations can provide reliable values of local magnetic moments, volumes and energies with atomic resolution, i.e., characteristics of vacancies which are experimentally available often only in an averaged manner. Moreover, it would be highly advantageous to apply in these disordered cases a suitable method, based on thermodynamics and statistical physics, which estimates temperature-dependent concentration of vacancies. In contrast to the case of vacancies in ordered intermetallics, which are characterized by a few individual values, broad ranges of vacancy formation energies (or better said, their statistical distributions) would be used as input.

Author Contributions: Conceptualization, I.M. and M.F.; Methodology, I.M., D.H. and N.K.; Resources, M.Š.; Writing-Original Draft Preparation, I.M. and M.F.; Writing_Review \& Editing, I.M., N.K., D.H. and M.Š.; Visualization, M.F. and I.M.; Supervision, M.Š. and M.F.; Project Administration and Funding Acquisition, M.Š. and M.F.

Funding: The authors acknowledge the Czech Science Foundation for the financial support received under the Project No. 17-22139S (M.F. and I.M.). Additional resources were provided by the Ministry of Education, Youth and Sports of the Czech Republic under the Project CEITEC 2020, LQ1601 (M.Š).

Acknowledgments: M.F., I.M. and M.Š. also acknowledge supports from the Academy of Sciences of the Czech Republic (Institutional Project No. RVO:68081723) and the Ministry of Education, Youth and Sports of the Czech Republic via the research infrastructure IPMINFRA, LM2015069. Computational resources were made available by the Ministry of Education, Youth and Sports of the Czech Republic under the Projects CESNET (Project No. LM2015042), CERIT-Scientific Cloud (Project No. LM2015085) and IT4Innovations National Supercomputer Center (Project No. LM2015070) within the program Projects of Large Research, Development and Innovations Infrastructures. Special quasi-random distribution of atoms was obtained using the USPEX code [74-76], based on an evolutionary algorithm developed by Oganov, Glass, Lyakhov and Zhu and featuring local optimization, real-space representation and flexible physically motivated variation operators. Figures 1 and 2 were visualized using the VESTA package [87]. We also acknowledge very fruitful discussions with Dr. Yvonna Jirásková from IPM in Brno.

Conflicts of Interest: The authors declare no conflict of interest.

\section{Appendix A}

Our above discussed quantum-mechanical calculations of the vacancy formation energies and vacancy-related properties were all performed in a way that the shape and volume of supercells containing defects were changed so as to minimize the total energy. This situation corresponds to a rather high concentration of vacancies and the surrounding matrix which is soft enough to respond to the vacancies. As a complement to these calculations we also test a scenario when the concentration of vacancies is very low and a large defect-free matrix further apart from a vacancy would be hard enough to keep the interatomic distances and volume as in the defect-free state. Methodologically, this case corresponds to the situation when the volume and the shape of supercells with vacancies are kept equal to those of the defect-free material. Only the internal atomic positions are allowed to change so as to minimize the forces acting upon them (and the total energy). The calculated vacancy formation energies are shown in Figure A1. The formation energies are higher than those summarized in Figure 3, but the above identified trend of decreasing vacancy formation with increasing concentration of $\mathrm{Al}$ atoms in the 1st coordination shell is clearly visible also in this case (see Figure A1a). 
(a)

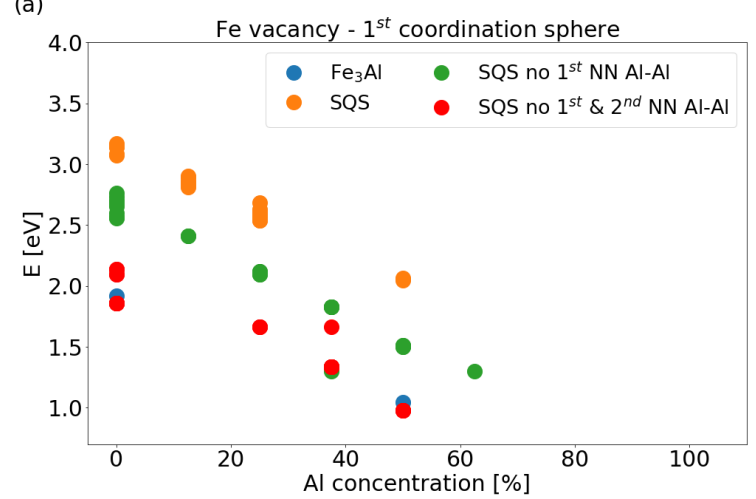

(b)

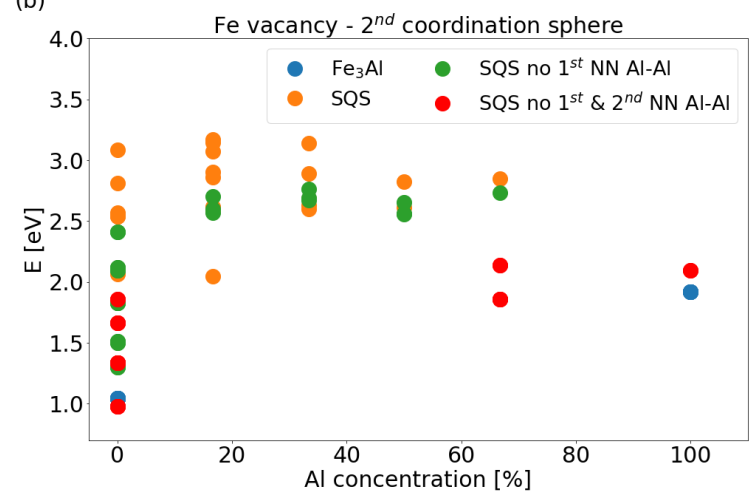

Figure A1. Vacancy formation energies calculated without changes in cell shape and volume as functions of concentration of $\mathrm{Al}$ atoms: for Fe vacancy (a) in the 1st (b) and the 2nd coordination shell.

\section{References}

1. Č́ížek, J.; Lukáč, F.; Melikhova, O.; Procházka, I.; Kužel, R. Thermal vacancies in $\mathrm{Fe}_{3} \mathrm{Al}$ studied by positron annihilation. Acta Mater. 2011, 59, 4068-4078. [CrossRef]

2. Č́ížek, J.; Lukáč, F.; Procházka, I.; Kužel, R.; Jirásková, Y.; Janičkovič, D.; Anwand, W.; Brauer, G. Characterization of quenched-in vacancies in Fe-Al alloys. Phys. B Condens. Matter 2012, 407, 2659-2664. [CrossRef]

3. Č́žzek, J. Characterization of lattice defects in metallic materials by positron annihilation spectroscopy: A review. J. Mater. Sci. Technol. 2018, 34, 577-598. [CrossRef]

4. James, P.; Eriksson, O.; Johansson, B.; Abrikosov, I.A. Calculated magnetic properties of binary alloys between Fe, Co, Ni, and Cu. Phys. Rev. B 1999, 59, 419-430. [CrossRef]

5. Mayer, J.; Meyer, B.; Oehrens, J.; Bester, G.; Börnsen, N.; Fähnle, M. Effective formation energies of atomic defects in $\mathrm{DO}_{3}-\mathrm{Fe}_{3} \mathrm{Al}$ : An ab-initio study. Intermetallics 1997, 5, 597-600. [CrossRef]

6. Kuriplach, J. Structure of Defects, their Interactions and Positron Characteristics in $\mathrm{Fe}_{3} \mathrm{Al}$ system. Phys. Procedia 2012, 35, 69-74. [CrossRef]

7. Deniszczyk, J.; Boroński, E.; Hanc, A. Effect of Vacancies on Positron Annihilation and Hyperfine Interactions in Fe-Al Alloys-Ab Initio Study. Solid Compounds of Transition Elements II. Trans Tech Publications. In Solid State Phenomena; Trans Tech Publications Ltd.: Zurich, Switzerland, 2013; Volume 194, pp. 272-275. [CrossRef]

8. Kentzinger, E.; Cadeville, M.C.; Pierron-Bohnes, V.; Petry, W.; Hennion, B. Lattice dynamics and migration enthalpies in iron-rich Fe-Al alloys and ordered and B2 compounds. J. Phys. Condens. Matter 1996, 8, 5535-5553. [CrossRef]

9. Gambino, D.; Alling, B. Lattice relaxations in disordered Fe-based materials in the paramagnetic state from first principles. Phys. Rev. B 2018, 98, 064105. [CrossRef]

10. Koutná, N.; Holec, D.; Friák, M.; Mayrhofer, P.H.; Šob, M. Stability and elasticity of metastable solid solutions and superlattices in the MoN-TaN system: First-principles calculations. Mater. Des. 2018, 144, 310-322. [CrossRef]

11. Mirzoev, A.A.; Mirzaev, D.A.; Verkhovykh, A.V. Hydrogen-vacancy interactions in ferromagnetic and paramagnetic bcc iron: Ab initio calculations. Phys. Status Solidi B Basic Solid State Phys. 2015, 252, 1966-1970. [CrossRef]

12. Marceau, R.K.W.; Ceguerra, A.V.; Breen, A.J.; Palm, M.; Stein, F.; Ringer, S.P.; Raabe, D. Atom probe tomography investigation of heterogeneous short-range ordering in the 'komplex' phase state (K-state) of Fe-18Al (at.\%). Intermetallics 2015, 64, 23-31. [CrossRef]

13. Gorbatov, O.I.; Gornostyrev, Y.N.; Korzhavyi, P.A.; Ruban, A.V. Ab initio modeling of decomposition in iron based alloys. Phys. Metals Metallogr. 2016, 117, 1293-1327. [CrossRef]

14. Nandipati, G.; Jiang, X.; Vemuri, R.S.; Mathaudhu, S.; Rohatgi, A. Self-learning kinetic Monte Carlo simulations of diffusion in ferromagnetic $\alpha$-Fe-Si alloys. J. Phys. Condens. Matter 2018, 30. [CrossRef] 
15. Kulikov, N.; Postnikov, A.; Borstel, G.; Braun, J. Onset of magnetism in B2 transition-metal aluminides. Phys. Rev. B 1999, 59, 6824-6833. [CrossRef]

16. Jaglicic, Z.; Jagodic, M.; Grushko, B.; Zijlstra, E.S.; Weber, T.; Steurer, W.; Dolinsek, J. The effect of thermal treatment on the magnetic state and cluster-related disorder of icosahedral Al-Pd-Mn quasicrystals. Intermetallics 2010, 18, 623-632. [CrossRef]

17. Huang, S.; Worthington, D.L.; Asta, M.; Ozolins, V.; Ghosh, G.; Liaw, P.K. Calculation of impurity diffusivities in $\alpha$-Fe using first-principles methods. Acta Mater. 2010, 58, 1982-1993. [CrossRef]

18. Muzyk, M.; Nguyen-Manh, D.; Kurzydlowski, K.J.; Baluc, N.L.; Dudarev, S.L. Phase stability, point defects, and elastic properties of W-V and W-Ta alloys. Phys. Rev. B 2011, 84. [CrossRef]

19. Piochaud, J.B.; Klaver, T.P.C.; Adjanor, G.; Olsson, P.; Domain, C.; Becquart, C.S. First-principles study of point defects in an fcc Fe-10Ni-20Cr model alloy. Phys. Rev. B 2014, 89. [CrossRef]

20. Liu, H.Y; Wang, J.J.; Jin, J.F.; Liu, C.M.; Zhang, H.Y. A first-principles investigation on the effect of the divacancy defect on magnetic properties of $\mathrm{Fe}_{94} \mathrm{~V}_{6}$ alloy. J. Appl. Phys. 2018, 124, 163904. [CrossRef]

21. Schneider, A.; Fu, C.C.; Barreteau, C. Local environment dependence of Mn magnetism in bcc iron-manganese alloys: A first-principles study. Phys. Rev. B 2018, 98, 094426. [CrossRef]

22. Ho, K.; Dodd, R. Point-defects in FeAl. Scr. Metall. 1978, 12, 1055-1058. [CrossRef]

23. Chang, Y.; Pike, L.; Liu, C.; Bilbrey, A.; Stone, D. Correlation of the hardness and vacancy concentration in FeAl. Intermetallics 1993, 1, 107-115. [CrossRef]

24. Krachler, R.; Ipser, H.; Sepiol, B.; Vogl, G. Diffusion mechanism and defect concentrations in $\beta^{\prime}$-FeAl, an intermetallic compound with B2 structure. Intermetallics 1995, 3, 83-88. [CrossRef]

25. Hotar, A.; Kejzlar, P.; Palm, M.; Minarik, J. The effect of Zr on high-temperature oxidation behaviour of $\mathrm{Fe}_{3} \mathrm{Al}$-based alloys. Corros. Sci. 2015, 100, 147-157. [CrossRef]

26. Brito, P.; Schuller, E.; Silva, J.; Campos, T.; de Araujo, C.R.; Carneiro, J.R. Electrochemical corrosion behaviour of (100), (110) and (111) $\mathrm{Fe}_{3}$ A single crystals in sulphuric acid. Corros. Sci. 2017, 126, 366-373. [CrossRef]

27. Sauthoff, G. Intermetallics; VCH Verlagsgesellschaft: Weinheim, Germany, 1995.

28. Liu, C.T.; Stringer, J.; Mundy, J.N.; Horton, L.L.; Angelini, P. Ordered intermetallic alloys: An assessment. Intermetallics 1997, 5, 579-596. [CrossRef]

29. Stoloff, N.S. Iron aluminides: Present status and future prospects. Mater. Sci. Eng. A 1998, 258, 1-14. [CrossRef]

30. Liu, C.T.; Lee, E.H.; McKamey, C.G. An environmental-effect as the major cause for room-temperature embrittlement in FeAl. Scr. Metall. Mater 1989, 23, 875-880. [CrossRef]

31. Lynch, R.J.; Heldt, L.A.; Milligan, W.W. Effects of alloy composition on environmental embrittlement of B2 ordered iron aluminides. Scr. Metall. Mater 1991, 25, 2147-2151. [CrossRef]

32. Liu, C.T.; McKamey, C.G.; Lee, E.H. Environmental-effects on room-temperature ductility and fracture in $\mathrm{Fe}_{3} \mathrm{Al}$. Scr. Metall. Mater 1990, 24, 385-389. [CrossRef]

33. Lynch, R.J.; Gee, K.A.; Heldt, L.A. Environmental embrittlement of single-crystal and thermomechanically processed B2-ordered iron aluminides. Scr. Metall. Mater 1994, 30, 945-950. [CrossRef]

34. Li, X.; Prokopcakova, P.; Palm, M. Microstructure and mechanical properties of Fe-Al-Ti-B alloys with additions of Mo and W. Mater. Sci. Eng. A Struct. Mater. Prop. Microstruct. Process. 2014, 611, $234-241$. [CrossRef]

35. Azmi, S.A.; Michalcova, A.; Sencekova, L.; Palm, M. Microstructure and mechanical properties of Fe-Al-Nb-B alloys. MRS Adv. 2017, 2, 1353-1359. [CrossRef]

36. Lazinska, M.; Durejko, T.; Czujko, T.; Bojar, Z. The Effect of the Traverse Feed Rate on the Microstructure and Mechanical Properties of Laser Deposited $\mathrm{Fe}_{3} \mathrm{Al}(\mathrm{Zr}, \mathrm{B})$ Intermetallic Alloy. Materials 2018, 11, 792. [CrossRef] [PubMed]

37. Kratochvíl, P.; Daniš, S.; Minárik, P.; Pešička, J.; Král, R. Strengthening of $\mathrm{Fe}_{3} \mathrm{Al}$ Aluminides by One or Two Solute Elements. Metall. Mater. Trans. A Phys. Metall. Mater. Sci. 2017, 48A, 4135-4139. [CrossRef]

38. Zamanzade, M.; Barnoush, A.; Motz, C. A Review on the Properties of Iron Aluminide Intermetallics. Crystals 2016, 6, 10. [CrossRef]

39. Dobeš, F.; Dymáček, P.; Friák, M. Small punch creep of Fe-Al-Cr alloy with Ce addition and its relation to uniaxial creep tests. Kov. Mater.-Met. Mater. 2018, 56, 205-212. [CrossRef] 
40. Jiraskova, Y.; Pizurova, N.; Titov, A.; Janickovic, D.; Friak, M. Phase separation in Fe-Ti-Al alloy-Structural, magnetic, and Mossbauer study. J. Magn. Magn. Mater. 2018. [CrossRef]

41. Dymáček, P.; Dobeš, F.; Jirásková, Y.; Pizúrová, N.; Friák, M. Tensile, creep and fracture testing of prospective Fe-Al-based alloys using miniature specimens. Theor. Appl. Fract. Mech. 2019, 99, 18-26. [CrossRef]

42. Šesták, P.; Friák, M.; Holec, D.; Všianská, M.; Šob, M. Strength and Brittleness of Interfaces in Fe-Al Superalloy Nanocomposites under Multiaxial Loading: An ab initio and Atomistic Study. Nanomaterials 2018, 8, 873. [CrossRef] [PubMed]

43. Rank, M.; Franke, P.; Seifert, H.J. Thermodynamic investigations in the Al-Fe system: Thermodynamic modeling using CALPHAD. Int. J. Mater. Res. 2019, 110, 1-16. [CrossRef]

44. Kratochvíl, P.; Pešička, J.; Král, R.; Švec, M.; Palm, M. Evaluation of solid-solution hardening of Fe-27 at. pct Al by vanadium and comparison to precipitation strengthening by vanadium carbides. Metall. Mater. Trans. A Phys. Metall. Mater. Sci. 2015, 46A, 5091-5094. [CrossRef]

45. Senčeková, L.; Palm, M.; Pešička, J.; Veselý, J. Microstructures, mechanical properties and oxidation behaviour of single-phase $\mathrm{Fe}_{3} \mathrm{Al}\left(\mathrm{D0}_{3}\right)$ and two-phase $\alpha-\mathrm{Fe}-\mathrm{Al}(\mathrm{A} 2)+\mathrm{Fe}_{3} \mathrm{Al}\left(\mathrm{D0}_{3}\right)$ Fe-Al-V alloys. Intermetallics 2016, 73, 58-66. [CrossRef]

46. Shahid, R.N.; Scudino, S. Strengthening of Al-Fe $3 \mathrm{Al}$ composites by the generation of harmonic structures. Sci. Rep. 2018, 8. [CrossRef] [PubMed]

47. Verona, M.N.; Setti, D.; Cortes Paredes, R.S. Microstructure and Properties of $\mathrm{Fe}_{3} \mathrm{Al}-\mathrm{Fe}_{3} \mathrm{AlC}$ (x) Composite Prepared by Reactive Liquid Processing. Metall. Mater. Trans. B Process Metall. Mater. Process. Sci. 2018, 49, 529-536. [CrossRef]

48. Prakash, U. Intermetallic matrix composites based on iron aluminides. In Intermetallic Matrix Composites: Properties and Applications; Mitra, R., Ed.; Woodhead Publishing Series in Composites Science and Engineering; Woodhead Publishing: Sawston, Cambridge, UK, 2018; pp. 21-35. [CrossRef]

49. Sharifitabar, M.; Khaki, J.V.; Sabzevar, M.H. Formation mechanism of $\mathrm{TiC}-\mathrm{Al}_{2} \mathrm{O}_{3}-\mathrm{Fe}_{3} \mathrm{Al}$ composites during self-propagating high-temperature synthesis of $\mathrm{TiO}_{2}$-Al-C-Fe system. Ceram. Int. 2016, 42, 12361-12370. [CrossRef]

50. Duan, X.; Gao, S.; Dong, Q.; Zhou, Y.; Xi, M.; Xian, X.; Wang, B. Reinforcement mechanism and wear resistance of $\mathrm{Al}_{2} \mathrm{O}_{3} / \mathrm{Fe}-\mathrm{Cr}-\mathrm{Mo}$ steel composite coating produced by laser cladding. Surf. Coat. Technol. 2016, 291, 230-238. [CrossRef]

51. Kong, J.; Wei, Y.; Li, J.; Huang, J.; Wang, T. Microwave-assisted combustion synthesis of $\mathrm{Fe}_{3} \mathrm{Al}$ bulk nanocrystalline intermetallic matrix composites. Adv. Powder Technol. 2015, 26, 778-782. [CrossRef]

52. Imandoust, A.; Zarei-Hanzaki, A.; Ou, K.L.; Yu, C.H. $\mathrm{D0}_{3}$ Ordered Phase Strengthening in Dual Phase Twinning-Induced Plasticity Steel. J. Mater. Eng. Perform. 2015, 24, 2085-2090. [CrossRef]

53. Cheng, J.; Yin, B.; Qiao, Z.; Yang, J.; Liu, W. Mechanical and dry-sliding tribological properties of $\mathrm{Fe}_{3} \mathrm{Al}$ based composites reinforced by novel $\mathrm{W}_{0.5} \mathrm{Al}_{0.5} \mathrm{C}_{0.5}$ particulates. Mater. Des. 2015, 66, 67-76. [CrossRef]

54. Molina, A.; Torres-Islas, A.; Serna, S.; Acosta-Flores, M.; Rodriguez-Diaz, R.A.; Colin, J. Corrosion, Electrical and Mechanical Performance of Copper Matrix Composites Produced by Mechanical Alloying and Consolidation. Int. J. Electrochem. Sci. 2015, 10, 1728-1741.

55. Bai, Y.; Xing, J.; Guo, Y.; Li, J.; He, Y.; Ma, S. Effect of Cr on Microstructure, Mechanical Properties, and Wear Behavior of In Situ 20 wt.\% $\mathrm{Al}_{2} \mathrm{O}_{3} / \mathrm{Fe}-25 \mathrm{Al}$ Composites. J. Mater. Eng. Perform. 2015, 24, 936-945. [CrossRef]

56. Panda, D.; Kumar, L.; Alam, S.N. Development of Al-Fe 3 Al Nanocomposite by Powder Metallurgy Route. Mater. Today Proc. 2015, 2, 3565-3574. [CrossRef]

57. Dobeš, F.; Kratochvíl, P.; Kejzlar, P. Creep of three-phase alloy Fe-30\%Al-5.2\%Zr. Kov. Mater. Met. Mater. 2015, 53, 127-132. [CrossRef]

58. Kattner, U.; Burton, B. Al-Fe (Aluminium-Iron). In Phase Diagrams of Binary Iron Alloys; Okamoto, H., Ed.; ASM International: Almere, The Netherlands, 1993; pp. 12-28.

59. Sundman, B.; Ohnuma, I.; Dupin, N.; Kattner, U.R.; Fries, S.G. An assessment of the entire Al-Fe system including $\mathrm{DO}_{3}$ ordering. Acta Mater. 2009, 57, 2896-2908. [CrossRef]

60. Fähnle, M.; Meyer, B.; Mayer, J.; Oehrens, J.; Bester, G. Diffusion in metals and intermetallic compounds: The impact of an-initio calculations. MRS Proc. 1998, 527, 23. [CrossRef]

61. Schaefer, H.E.; Würschum, R.; Šob, M.; Žák, T.; Yu, W.Z.; Eckert, W.; Banhart, F. Thermal vacancies and positron-lifetime measurements in $\mathrm{Fe}_{76.3} \mathrm{Al}_{23.7}$. Phys. Rev. B 1990, 41, 11869-11874. [CrossRef] 
62. Friák, M.; Deges, J.; Krein, R.; Frommeyer, G.; Neugebauer, J. Combined ab initio and experimental study of structural and elastic properties of $\mathrm{Fe}_{3} \mathrm{Al}$-based ternaries. Intermetallics 2010, 18, 1310. [CrossRef]

63. Muratov, L.S.; Cooper, B.R. Ab-initio based calculations of vacancy formation and clustering energies including lattice relaxation in $\mathrm{Fe}_{3} \mathrm{Al}$. MRS Proc. 1998, 538, 309. [CrossRef]

64. Hohenberg, P.; Kohn, W. Inhomogeneous electron gas. Phys. Rev. B 1964, 136, B864-B871. [CrossRef]

65. Kohn, W.; Sham, L.J. Self-consistent equations including exchange and correlation effects. Phys. Rev. A 1965, 140, A1133-A1138. [CrossRef]

66. Kresse, G.; Hafner, J. Ab initio molecular dynamics for liquid metals. Phys. Rev. B 1993, 47, 558-561. [CrossRef]

67. Kresse, G.; Furthmüller, J. Efficient iterative schemes for ab initio total-energy calculations using a plane-wave basis set. Phys. Rev. B 1996, 54, 11169-11186. [CrossRef]

68. Kresse, G.; Joubert, D. From ultrasoft pseudopotentials to the projector augmented-wave method. Phys. Rev. B 1999, 59, 1758-1775. [CrossRef]

69. Perdew, J.P.; Wang, Y. Accurate and simple analytic representation of the electron-gas correlation energy. Phys. Rev. B 1992, 45, 13244-13249. [CrossRef]

70. Blöchl, P.E. Projector augmented-wave method. Phys. Rev. B 1994, 50, 17953-17979. [CrossRef]

71. Vosko, S.H.; Wilk, L.; Nusair, M. Accurate spin-dependent electron liquid correlation energies for local spin density calculations: A critical analysis. Can. J. Phys. 1980, 58, 1200. [CrossRef]

72. Monkhorst, H.J.; Pack, J.D. Special points for Brillouin-zone integrations. Phys. Rev. B 1976, 13, 5188-5192. [CrossRef]

73. Zunger, A.; Wei, S.; Ferreira, L.; Bernard, J. Special quasirandom structures. Phys. Rev. Lett. 1990, 65, 353-356. [CrossRef] [PubMed]

74. Oganov, A.R.; Glass, C.W. Crystal structure prediction using ab initio evolutionary techniques: Principles and applications. J. Chem. Phys. 2006, 124, 244704. [CrossRef] [PubMed]

75. Lyakhov, A.O.; Oganov, A.R.; Stokes, H.T.; Zhu, Q. New developments in evolutionary structure prediction algorithm USPEX. Comput. Phys. Commun. 2013, 184, 1172-1182. [CrossRef]

76. Oganov, A.R.; Lyakhov, A.O.; Valle, M. How Evolutionary Crystal Structure Prediction Works-And Why. Acc. Chem. Res. 2011, 44, 227-237. [CrossRef] [PubMed]

77. Wolff, J.; Franz, M.; Hehenkamp, T. Defect analysis with positron annihilation-Applications to Fe aluminides. Microchim. Acta 1997, 125, 263-268. [CrossRef]

78. Friák, M.; Neugebauer, J. Ab initio study of the anomalous volume-composition dependence in Fe-Al alloys. Intermetallics 2010, 18, 1316-1321. [CrossRef]

79. Miháliková, I.; Slávik, A.; Friák, M.; Všianská, M.; Koutná, N.; Holec, D.; Šob, M. First-principles study of interface energies in Fe-Al-based superalloy nanocomposites. In Proceedings of the 9th International Conference on Nanomaterials-Research and Application, Brno, Czech Republic, 18-20 October 2017; pp. 69-74.

80. Miháliková, I.; Friák, M.; Jirásková, Y.; Holec, D.; Koutná, N.; Šob, M. Impact of Nano-Scale Distribution of Atoms on Electronic and Magnetic Properties of Phases in Fe-Al Nanocomposites: An Ab Initio Study. Nanomaterials 2018, 8, 1059. [CrossRef] [PubMed]

81. Ponomareva, A.V.; Gornostyrev, Y.N.; Abrikosov, I.A. Ab initio calculation of the solution enthalpies of substitutional and interstitial impurities in paramagnetic fcc Fe. Phys. Rev. B 2014, 90, 014439. [CrossRef]

82. Stefanowicz, S.; Kunert, G.; Simserides, C.; Majewski, J.A.; Stefanowicz, W.; Kruse, C.; Figge, S.; Li, T.; Jakieła, R.; Trohidou, K.N.; et al. Phase diagram and critical behavior of the random ferromagnet $\mathrm{Ga}_{1-x} \mathrm{Mn}_{x} \mathrm{~N}$. Phys. Rev. B 2013, 88, 081201. [CrossRef]

83. Priour, D.J.; Das Sarma, S. Critical behavior of diluted magnetic semiconductors: Apparent violation and eventual restoration of the Harris criterion for all regimes of disorder. Phys. Rev. B 2010, 81, 224403. [CrossRef]

84. Ozolins, V.; Wolverton, C.; Zunger, A. Cu-Au, Ag-Au, Cu-Ag, and Ni-Au intermetallics: First-principles study of temperature-composition phase diagrams and structures. Phys. Rev. B 1998, 57, 6427-6443. [CrossRef]

85. Müller, S. Bulk and surface ordering phenomena in binary metal alloys. J. Phys. Condens. Matter 2003, 15, R1429-R1500. [CrossRef] 
86. Tasnádi, F.; Lugovskoy, A.V.; Odén, M.; Abrikosov, I.A. Non-equilibrium vacancy formation energies in metastable alloys-A case study of $\mathrm{Ti}_{0.5} \mathrm{Al}_{0.5} \mathrm{~N}$. Mater. Des. 2017, 114, 484-493. [CrossRef]

87. Momma, K.; Izumi, F. VESTA 3 for three-dimensional visualization of crystal, volumetric and morphology data. J. Appl. Crystallogr. 2011, 44, 1272-1276. [CrossRef]

(C) 2019 by the authors. Licensee MDPI, Basel, Switzerland. This article is an open access article distributed under the terms and conditions of the Creative Commons Attribution (CC BY) license (http:/ / creativecommons.org/licenses/by/4.0/). 